\title{
Transformer failure diagnosis by different rule extraction method: a review
}

\author{
Anurag Tamrakar ${ }^{1 *}$ and V.B. Reddy ${ }^{2}$ \\ Research Scholar, Department of Electrical and Electronics, Swami Vivekanand University, Sagar, Madhya \\ Pradesh, India ${ }^{1}$ \\ Associate Professor, Department of Electrical and Electronics, Swami Vivekanand University, Sagar, Madhya \\ Pradesh, India ${ }^{2}$
}

\section{(C)2018 ACCENTS}

\begin{abstract}
In this paper study and analysis have been presented for the dissolved gas analysis (DGA). It is the crucial component for fault diagnosis in oil filled transformers. It is also important as the timely diagnosis may help in several directions including the cost. So several methods in the direction of efficient diagnosis and missing classification have been discussed. This paper provides the direction in finding the way to overcome the gaps and finding the chances to build an efficient framework for this diagnosis. This paper also provides the comparative study for the detail analysis of the methods used in the previous literature. It is also helpful in the explorations of the gaps, better method identification and finding in the better combination of methods used.
\end{abstract}

\section{Keywords}

DGA, Data mining, Fault diagnosis, Transformer.

\section{Introduction}

This paper addresses in the direction of dissolve gas analysis (DGA). Power transformers are intended to transmit and disseminate electrical power. Performing disconnected and obtrusive tests likewise add to the substitution cost. Subsequently, there is an expanding need to move from conventional calendar based upkeep projects to condition-based support. Mineral oils are blends of a wide range of hydrocarbon particles. They are made basically out of immersed hydrocarbon called paraffin whose general atomic recipe [1-3]. At the point when use in transformers, the oil goes about as a dielectric medium and furthermore as a warmth exchange operator. The breakdown of electrical protecting materials and related segments inside the transformer frees gases inside the unit. The dissemination of these gases can be identified with the kind of electrical blame, and the rate of gas age can show the seriousness of the blame [4]. Protecting oils experience the ill effects of crumbling, which can end up plainly deadly for transformers. Likewise, release in oil can make genuine harm the other protecting materials, making the observing of energy transformers protection a vital errand [5].

\footnotetext{
*Author for correspondence
}

While protecting oils and cellulose materials in receptive gear are subjected to higher than typical electrical or warm burdens, they decay to create certain flammable gases alluded to as blame gases [68].

For early blame conditions (i.e. gradually advancing flaw), the gases produced will be broken down into the oil some time before any free gas is amassed in the gas transfer. In this manner by breaking down oil test for broke up gas content it is conceivable to evaluate the state of the gear and identifying deficiencies at a beginning time. On the off chance that demonstrated, the sort of can be anticipated utilizing different examination strategies [9].

Countless are accessible for transformer wellbeing checking. In any case, an engaged approach is required for diagnostics [10]. Considering the long administration life of a power transformer and common utilization of human judgment (master), there is a need to structure a learning base around master information while proceeding to make new analytic abilities which can be connected to. This paper gives a review about how combination of information mining based methods can be utilized as a part of diagnostics of energy transformers. 


\section{Related work}

In 2006, Lin et al. [11] suggested that the climatic factors including temperature and relative humidity influenced the system load. They have used data mining algorithms to the china light and power (CLP) to analyse the effect of temperature and relative humidity on the peak load and the cluster of load profiles.

In 2007, Duraisamy et al. [12] proposed fuzzy system and neural network for the faults diagnosis in the power transformer using dissolved gas analysis (DGA) method. They have tested on the Electricity Board data. The fuzzy system is tested with triangular, trapezoidal and Gaussian membership functions furthermore, its adequacy is broke down through reproduction regarding exactness in distinguishing the transformer faults. Their proposed Back propagation network is checked to conquer the disadvantages of regular techniques.

In 2008, Zhang et al. [13] suggested Fisher rule to evaluate the performance of fault diagnosis method. The assessment of the outcomes shows that both of the two information pre-treatment techniques can accomplish the reason for huge contrast in the estimation of mean amongst classes and little distinction in scattering of a class. The DGA information of the disappointment transformers are dealt with by various standardization techniques as the preparation tests, and after that the specimens are prepared in the compound neural systems which utilize the $\mathrm{CP}$ calculation. The determination aftereffects of the test tests demonstrate that the new techniques may enhance the exactness of system determination.

In 2010, Rajamani et al. [14] proposed bacterial foraging-based approach for the fault characteristics diagnosis of dynamic insulation failure in transformer during impulse test. The winding streams procured by tank current technique amid drive test are examined for recognizable proof of blame qualities. The time- recurrence area based highlights removed from cross-wavelet spectra of twisting streams of protection fizzled and no-blame (solid) protection of transformer are given as contribution to the scrounging calculation for recognizable proof of dynamic protection disappointment attributes. The required twisting streams to remove the critical highlights are obtained by copying diverse dynamic protection disappointments in the created simple model of $33 \mathrm{kV}$ twisting of 3 MVA transformers. To copy different blame attributes in simple model, appropriate blame emulator modules have been produced. Results demonstrate that the proposed scavenging calculation with cross-wavelet change highlights could effectively distinguish the blame qualities of dynamic protection disappointment with satisfactory exactness.

In 2010, Siontorou et al. [15] proposed a novel realtime diagnostic expert scheme for field-effect transistor (FET)-based bio sensing. They have investigates the causes of sensor malfunctions by applying fault tree analysis (FTA). They have proposed a computer-aided method for diagnosing biosensor failure. Their tree structure serves as the knowledge base (KB), and the fuzzy-rules-based decision mechanism is the inference engine for fault detection and isolation.

In 2011, Rao et al. [16] developed a new fuzzy logic algorithm (FLA). It provides the vulnerability status of internal faults by considering thermal, electrical and mechanical conditions. For the reduction of misinterpretation the results of dissolved gas analysis, insulating oil break down voltage, and sweep frequency response has been analysed. Their system includes 10 fuzzy logic controllers and they are connected by thinking about specialized conditions and reasons, the run bases of these controllers were created by considering different norms and experience of TIFAC CORE in NIT-Hamirpur. Their proposed system is found to be highly precise in classifying the situations of any transformer, reducing aliasing effects and identifying the current prevailing conditions.

In 2012, Malik et al. [17] suggested that the UVSpectrophotometer used to determine the transformer integrity. The health of the transformer can be accurately identified by this. But they have suggested that it is not useful in all aspects as it only provides the pictorial information of the age of the oil. They have presented fuzzy logic method for the health assessment of the transformer oil. It provides the automatic and quick examination of transformer oil.

In 2012, Da et al. [18] presented a transformer failure diagnosis system based on DGA. It is done by the extraction of the rules from Kohonen Self-Organizing Map. In this process the Kohonen net was trained first. It is used to capture the knowledge from the faulty transformers. Then in the learning stage Zeroorder Takagi-Sugeno fuzzy rules has been transformed. They have also applied fuzzyfication process in the fuzzy system output. The results 
indicated that the obtained results as compared with other traditional methods are good.

In 2013, Da et al. [19] presented the results of a knowledge acquisition of vibrations in high-power transformers. The region they considered is the Amazon region, Brazil. They have analyses the vibrations by using the radial graphs. The results indicate that the largest mean vibration area occurred in the front of the transformer. These results have been used for the analysis of the vibration behavior. They have used statistical analyses and the repeated measure analysis. It is used for the progression of a fuzzy inference system. They have suggested that this method is low-cost analyses techniques.

In 2013, Malik et al. [20] examined the effectiveness of neuro-fuzzy scheme (NFS) to identify the deterioration of the winding insulation paper (WIP) in power transformer. The correlation of meeting attributes of IEEE and IEC approach uncover that the NFS approach is very speedier in examinations prompting decrease in computational weight and offer ascent to negligible PC asset use. Concurrent ID of disintegration of the WIP and working conditions in oil-inundated power transformer has never been endeavoured in the past utilizing NFS. The strategy proposed in this paper gives not just best powerful reaction for the weakening of the WIP analysis and condition evaluation of energy transformer yet in addition show its fitting upkeep situation too. This approach will deliver a proactive statement to the power utilities for compelling acknowledgment of electrical soundness of oil-submerged power transformer under thought.

In 2014, Chao et al. [21] presented a life estimation model. This model has the advantages of the fault mechanism and the knowledge fitting laws of export system. It is also helpful in the collection of the information representing the insulation aging and type's reclassification. Based on this a multiobjective evaluating model has been suggested for power transformers life estimation. They have established life span evaluating decision model based on information fusion for multi-parameter power transformer. The lifetime trademark parameters from a wide range of sources are coordinated to fill in as the base layer of the multi-layer choice model, which improves the proficiency and dependability of this model. It gives a reference to drafting ideal upkeep conspire, accomplishing the point of condition based support and power utilities life forecast.
In 2015, Duan et al. [22] suggested that the mechanical failure is the main fault of transformer on-load tap-changers (OLTC). They have presented fuzzy C-Means (FCM) algorithm for the detection of OLTC faults in timely manner. Embedding dimension and delay time have been obtained by applying Cao's method. Proposed method has been used for the analysis of the vibration signals in high dimension space. The results shows that the centroids distributions of each condition vary greatly and the different lengths and angles of centroid vectors can be regarded as the judgment criterion quantitatively.

In 2016, Pengfei et al. [23] focused on the condition assessment of transformer bushing. They have constructed a fuzzy membership function to describe the factor layer. As per the fluffy assessment comes about, the first essential likelihood task, which is utilized for basic leadership model of evidential thinking, is resolved. In this way the fundamental likelihood task is gotten by prove thinking, lastly the evaluation comes about are resolved in view of the choice tenets of the most extreme essential likelihood task work. A few illustrations demonstrate that this strategy is precise and dependable.

In 2016, Tang et al. [24] suggested that the transformer fault diagnosis is an important factor in the transformer maintenance. The identification of the type of failure is tough as the encoded value is too severe. For finding the fault diagnosis rate FCM algorithm has been introduced. They have optimized FCM in two ways; first the outlier factor detection algorithm weakens the adverse impacts caused by anomaly factors in the dataset amid bunching process. Also, the factor in the target capacity of FCM calculation is utilized to expand the distinction of group protest and group focus. Their results proved that the improved FCM algorithm has a higher correct rate than traditional methods.

In 2014, Ramesh et al. [25] suggested that the inter turn short circuit faults is the main causes of power transformer failures. They have suggested a physical model of a multi-winding power transformer of 100 MVA, $138 / 13.8 \mathrm{KV}$. It is simulated in a power system. Diverse rates of turns for example, $1 \%, 3 \%$, $5 \%, 10 \%, 15 \%$, and $25 \%$ are shorted on essential and auxiliary sides of the multilinking transformer to measure the terminals current. The adjustment in the terminals current amid blame occurrence is insignificantly little. In order to encounter noteworthy changes, negative grouping streams are separated utilizing symmetrical segment approach. 
Magnitudes of negative sequence currents (\%MAG) and the corresponding phase shifts (PS) have been analysed. This is used as the inputs to fuzzy logic. They have built fuzzy inference engine with nine fuzzy rules based on the knowledge gained from the system behavior.

In 2016, Rigatos et al. [26] suggested that the online monitoring of electric power transformers provides correct indication of the status and ageing behavior. They have proposed neural modeling and the local statistical approach for the fault detection in power transformers. The neural-fuzzy network is used to model thermal condition of the power transformer in fault-free operation. The results in terms of performance of their method are validated through simulation experiments.

In 2016, Ghoneim et al. [27] suggested that the dissolved gas analysis (DGA) is the crucial technique to detect the faults in the oil-filled power transformers. They have proposed a new DGA approach to solve the problems of traditional techniques. They have analysed 386 dissolved gas samples from the Egyptian electric utility chemical laboratory as well as from credited literatures. These data sets are used for the testing of the model accuracy. Their results have been compared with the IEC Standard Code, Duval triangle and Rogers methods for the collected data set.

In 2017, Zarkovic et al. [28] suggested that the main problem in the diagnosis of power transformer that the exact interpretation of failure detection is tough. They have presented method based on artificial intelligence to overcome this problem. It can help in the transformers fault detection and classification.
They have analyzed and study the application of Mamdanil and Sugeno in fuzzy expert system. It is a collective case study of one unique and five separate controllers. The first case had shown the results of on-line and off-line transformer tests: age, the overheating temperature of the hot spot, frequency response analysis, temperature of insulation and dissolved gas-in-oil analysis. The second case shows the results of the previous measurements along with the observation of cumulative probability of occurrence of the faults.

In 2017, Islam et al. [29] suggested that the health index calculations are important in transmission network. They have evaluated general regression neural network (GRNN) having nonlinear property and helpful in measurements without quantization. The capability of GRNN is the multi-dimensional measurements. It is combined through an optimal weighting and scoring system to compute a quantitative health index of power transformers. It is tested based on the smoothly interpolated continuous function. Their results suggest that their method is capable and reliable in condition assessment of transformers.

\section{Study analysis}

In this section an analysis has been presented based on the related reviews. Table 1 shows the method analysis table. This table describes the method, the approach used and the gaps based on the analysis of their method, results and future work suggested. This provides an overall view of the work along with the methodology impact and the contribution parameters used for the compariosn.

Table 1Method analysis

\begin{tabular}{|c|c|c|c|c|}
\hline S.No & Reference & Method & Approach & Problem statement \\
\hline 1 & {$[30]$} & $\begin{array}{lr}\text { Data mining for oil- } \\
\text { insulated } & \text { power } \\
\text { transformers } & \end{array}$ & $\begin{array}{l}\text { They have reviewed different data mining } \\
\text { approaches in the direction of power } \\
\text { transformer maintenance. They have } \\
\text { discussed different data mining approaches } \\
\text { including expert systems, fuzzy logic, neural } \\
\text { networks, classification and decision, and } \\
\text { hybrid intelligent-based diagnostic systems. } \\
\text { They have suggested the applicability of these } \\
\text { methods for the DGA database. }\end{array}$ & $\begin{array}{l}\text { Practical exploartion is } \\
\text { missng. }\end{array}$ \\
\hline 2 & {$[31]$} & $\begin{array}{l}\text { Fault diagnosis of power } \\
\text { transformers using } \\
\text { computational intelligence }\end{array}$ & $\begin{array}{l}\text { They have studied and review computational } \\
\text { intelligence (CI) approaches for power } \\
\text { transformer. They have suggeested that CI- } \\
\text { based are highly effective for DG) data for } \\
\text { diagnosing transformer faults. }\end{array}$ & $\begin{array}{l}\text { They have suggested that } \\
\text { the missing combinations } \\
\text { of gas ratios may be } \\
\text { explored as the future } \\
\text { direction. }\end{array}$ \\
\hline 3 & {$[32]$} & $\begin{array}{l}\text { State assessment system of } \\
\text { power } \quad \text { transformer }\end{array}$ & $\begin{array}{l}\text { For the transformer condition checking } \\
\text { statistics-based association rule mining have }\end{array}$ & $\begin{array}{l}\text { Attribute base individual } \\
\text { information gathering can }\end{array}$ \\
\hline
\end{tabular}




\begin{tabular}{|c|c|c|c|c|}
\hline S.No & Reference & Method & Approach & Problem statement \\
\hline & & $\begin{array}{l}\text { equipments based on data } \\
\text { mining and fuzzy theory }\end{array}$ & $\begin{array}{l}\text { been applied for data preprocessing. At that } \\
\text { point a product stage that incorporates } \\
\text { usefulness to gather and store trial } \\
\text { information, dissect information and pattern, } \\
\text { create appraisal report and set forward } \\
\text { recommendations on repairing of transformer } \\
\text { hardware status is assembled. }\end{array}$ & aslo be useful. \\
\hline 4 & {$[33]$} & $\begin{array}{l}\text { Intelligent condition } \\
\text { monitoring and asset } \\
\text { management }\end{array}$ & $\begin{array}{l}\text { They have suggested condition monitoring } \\
\text { system for power transformers. They have } \\
\text { described a condition monitoring architecture } \\
\text { that is helpful in the interpretation of } \\
\text { diagnostic data. }\end{array}$ & $\begin{array}{l}\text { This interpretation can be } \\
\text { extended by using } \\
\text { evolutionary algorithm. }\end{array}$ \\
\hline 5 & {$[34]$} & $\begin{array}{l}\text { Data mining approach to } \\
\text { dissolved gas analysis }\end{array}$ & $\begin{array}{l}\text { They have applied genetic algorithm tuned } \\
\text { wavelet networks (GAWNs) for data mining } \\
\text { of DGA data. Their GAWNs can distinguish } \\
\text { the intricate relations between the } \\
\text { disintegrated gas substance of transformer oil } \\
\text { and comparing shortcoming writes. The } \\
\text { proposed GAWNs have been tried on the } \\
\text { Taipower Company's symptomatic records, } \\
\text { utilizing four analysis criteria, and contrasted } \\
\text { and counterfeit neural systems (ANNs) and } \\
\text { customary techniques. }\end{array}$ & $\begin{array}{l}\text { Other techniues can be } \\
\text { compared and validated. }\end{array}$ \\
\hline 6 & {$[35]$} & $\begin{array}{l}\text { Analysis of power } \\
\text { transformer dissolved gas } \\
\text { data }\end{array}$ & $\begin{array}{l}\text { They have introduced an approach for the } \\
\text { analysis of dissolved gas data for better and } \\
\text { convincing interpretation and fault diagnosis. } \\
\text { Their proposed approach is the combination } \\
\text { of data mining and the self-organizing map. }\end{array}$ & $\begin{array}{l}\text { Classifiers can be used to } \\
\text { classify the data in the } \\
\text { related faults. }\end{array}$ \\
\hline 7 & {$[36]$} & $\begin{array}{l}\text { Association Rule Mining- } \\
\text { Based Dissolved Gas } \\
\text { Analysis }\end{array}$ & $\begin{array}{l}\text { They have presented an association rule } \\
\text { mining (ARM)-based DGA approach to fault } \\
\text { diagnosis of power transformers. In the } \\
\text { improvement of the ARM-based DGA } \\
\text { approach, a property choice technique and a } \\
\text { consistent datum characteristic discretization } \\
\text { strategy are utilized for picking client } \\
\text { intrigued ARM properties from a DGA } \\
\text { informational index, i.e. the things that are } \\
\text { utilized to remove affiliation rules. The given } \\
\text { DGA informational index is made out of two } \\
\text { sections, i.e. preparing and test DGA } \\
\text { informational collections. An ARM } \\
\text { calculation to be specific Apriori-Total From } \\
\text { Partial is proposed for creating an affiliation } \\
\text { govern set (ARS) from the preparation DGA } \\
\text { informational collection. A short time later, an } \\
\text { ARS rearrangements technique and a run } \\
\text { wellness assessment strategy are used to } \\
\text { choose helpful principles from the ARS and } \\
\text { allocate a wellness incentive to each of the } \\
\text { valuable tenets, individually. }\end{array}$ & $\begin{array}{l}\text { Classifiers can be used to } \\
\text { classify the data in the } \\
\text { related faults. }\end{array}$ \\
\hline 8 & {$[37]$} & $\begin{array}{l}\text { Dissolved gas analysis } \\
\text { technique for incipient } \\
\text { fault diagnosis }\end{array}$ & $\begin{array}{l}\text { They have surveyed different techniques in } \\
\text { the DGA with different methodologies. }\end{array}$ & $\begin{array}{l}\text { Practical exploartion is } \\
\text { missng. }\end{array}$ \\
\hline
\end{tabular}




\section{Problem statement}

In the above section several analyses on different methods have been presented. Based on this the main problem statement are as follows:

1. There is a need of efficient framework for the fault detection based on DGA method.

2. The combination of data mining and optimization techniques can be helpful as it can help in class level classification.

3. Missing combinations of gas ratios is needed to be explored.

4. Classifiers can be used to classify the data in the related faults.

5. Attribute base individual information gathering is missing.

6. Combinations of gas ratios may be explored as it can be helpful in the combined exploration and fault diagnosis.

\section{Conclusion}

This paper addresses the DGA analysis in three different ways. First the detail study and analysis have been presented based on the pervious literature along with the method used. Second to provide the comparative study to highlights the gaps and the advantages of the methods. Third the analytical analysis has been present which is missing in the previous research which will help in the extension of the fault diagnosis work for the researchers.

\section{Acknowledgment}

None.

\section{Conflicts of interest}

The authors have no conflicts of interest to declare.

\section{References}

[1] DiGiorgio JB. Dissolved gas analysis of mineral oil insulating fluids. DGA Expert System: A Leader in Quality, Value and Experience. 2005; 1:1-7.

[2] Netam G, Yadav A. Fault detection, classification and section identification on distribution network with DSTATCOM using ANN. International Journal of Advanced Technology and Engineering Exploration. 2016; 3(23):150-7.

[3] Sarma DS, Kalyani GN. ANN approach for condition monitoring of power transformers using DGA. In TENCON. IEEE region 10 conference 2004 (pp. 4447). IEEE

[4] Pateriya A, Saxena N, Tiwari M. Transfer capability enhancement of transmission line using static synchronous compensator. International Journal of Advanced Computer Research. 2012; 2(7):83-8.

[5] Khinchi A, Prasad MP. Control of electronic throttle valve using model predictive control. International
Journal of Advanced Technology and Engineering Exploration. 2016; 3(22):118-24.

[6] Sun HC, Huang YC, Huang CM. A review of dissolved gas analysis in power transformers. Energy Procedia. 2012; 14:1220-5.

[7] Gayakwad DR, Mehta CR, Desai SP. Automatic reactive power control using FC-TCR. International Journal of Advanced Computer Research. 2014; 4(15):476-80.

[8] Kotsiantis S, Kanellopoulos D. Association rules mining: a recent overview. GESTS International Transactions on Computer Science and Engineering. 2006; 32(1):71-82.

[9] Dwivedi CK, Daigavane MB. Evaluation of moisture content in paper-oil of aged power transformer using RVM. In international conference on emerging trends in engineering and technology 2009 (pp. 470-5). IEEE.

[10] Sakala JD, Daka JS. General fault admittance method solution of a line-to-line fault. International Journal of Advanced Computer Research. 2013; 3(13):130-8.

[11] Lin JK, Tso SK, Ho HK, Mak CM, Yung KM, Ho YK. Study of climatic effects on peak load and regional similarity of load profiles following disturbances based on data mining. International Journal of Electrical Power \& Energy Systems. 2006; 28(3):177-85.

[12] Duraisamy V, Devarajan N, Somasundareswari D, Vasanth AA, Sivanandam SN. Neuro fuzzy schemes for fault detection in power transformer. Applied Soft Computing. 2007; 7(2):534-9.

[13] Zhang WZ, Wang ZG, Rong J, Kuang S, Zhang G. The application of compound networks in fault diagnosis of power transformer. In China international conference on electricity distribution 2008 (pp. 1-5). IEEE.

[14] Rajamani P, Dey D, Chakravorti S. Classification of dynamic insulation failures in transformer winding during impulse test using cross-wavelet transform aided foraging algorithm. IET Electric Power Applications. 2010; 4(9):715-26.

[15] Siontorou CG, Batzias FA, Tsakiri V. A knowledgebased approach to online fault diagnosis of FET biosensors. IEEE Transactions on Instrumentation and Measurement. 2010; 59(9):2345-64.

[16] Rao UM, Reddy MV, Jarial RK. Fuzzy logic based system to diagnose internal faults of power transformer. In international conference on communication and industrial application 2011 (pp. 15). IEEE.

[17] Malik H, Singh S, Kr M, Jarial RK. UV/VIS response based fuzzy logic for health assessment of transformer oil. Procedia Engineering. 2012; 30:905-12.

[18] Da Silva AC, Castro AR, Miranda V. Transformer failure diagnosis by means of fuzzy rules extracted from Kohonen self-organizing map. International Journal of Electrical Power \& Energy Systems. 2012; 43(1):1034-42.

[19] Da Silva Noronha T, De Oliveira TF, Da Silveira AM, Da Silva RR, Saraiva AC. Knowledge acquisition of 
vibrations in high-power transformers using statistical analyses and fuzzy approaches-a case study. Electric Power Systems Research. 2013; 104:110-5.

[20] Malik H, Yadav AK, Mishra S, Mehto T. Application of neuro-fuzzy scheme to investigate the winding insulation paper deterioration in oil-immersed power transformer. International Journal of Electrical Power \& Energy Systems. 2013; 53:256-71.

[21] Chao W, Yun-Cai L, Bi-jun C, You-yuan W. A multilayer power transformer life span evaluating decision model based on information fusion. In international conference on high voltage engineering and application 2014 (pp. 1-4). IEEE.

[22] Duan R, Wang F. Mechanical condition monitoring of on-load tap-changers using chaos theory \& fuzzy cmeans algorithm. In power \& energy society general meeting 2015 (pp. 1-5). IEEE.

[23] Pengfei J, Chao W, Jianxin G, Xinru Y, Shaojun C, Ting $\mathrm{H}$. The condition assessment of transformer bushing based on fuzzy logic. In international conference on condition monitoring and diagnosis 2016 (pp. 469-72). IEEE.

[24] Tang S, Peng G, Zhong Z. An improved fuzzy Cmeans clustering algorithm for transformer fault. In China international conference on electricity distribution 2016 (pp. 1-5). IEEE.

[25] Ramesh K, Sushama M. Inter-turn fault detection in power transformer using fuzzy logic. In international conference on science engineering and management research 2014 (pp. 1-5). IEEE.

[26] Rigatos G, Siano P. Power transformers' condition monitoring using neural modeling and the local statistical approach to fault diagnosis. International Journal of Electrical Power \& Energy Systems. 2016; 80:150-9.

[27] Ghoneim SS, Taha IB. A new approach of DGA interpretation technique for transformer fault diagnosis. International Journal of Electrical Power \& Energy Systems. 2016; 81:265-74.

[28] Žarković M, Stojković Z. Analysis of artificial intelligence expert systems for power transformer condition monitoring and diagnostics. Electric Power Systems Research. 2017; 149:125-36.

[29] Islam MM, Lee G, Hettiwatte SN. Application of a general regression neural network for health index calculation of power transformers. International Journal of Electrical Power \& Energy Systems. 2017; 93:308-15.
[30] Huang YC, Huang CM, Sun HC. Data mining for oilinsulated power transformers: an advanced literature survey. Wiley Interdisciplinary Reviews: Data Mining and Knowledge Discovery. 2012; 2(2):138-48.

[31] Sun HC, Huang YC, Huang CM. Fault diagnosis of power transformers using computational intelligence: a review. Energy Procedia. 2012; 14:1226-31.

[32] Zhong W, Sun Y, Xu M, Liu J. State assessment system of power transformer equipments based on data mining and fuzzy theory. In international conference on intelligent computation technology and automation 2010 (pp. 372-5). IEEE.

[33] Judd MD, McArthur SD, McDonald JR, Farish O. Intelligent condition monitoring and asset management, partial discharge monitoring for power transformers. Power Engineering Journal. 2002; 16(6):297-304.

[34] Huang YC. A new data mining approach to dissolved gas analysis of oil-insulated power apparatus. IEEE Transactions on Power Delivery. 2003; 18(4):1257-61.

[35] Thang KF, Aggarwal RK, McGrail AJ, Esp DG. Analysis of power transformer dissolved gas data using the self-organizing map. IEEE Transactions on Power Delivery.2003; 18(4):1241-8.

[36] Yang Z, Tang WH, Shintemirov A, Wu QH. Association rule mining-based dissolved gas analysis for fault diagnosis of power transformers. IEEE Transactions on Systems, Man, and Cybernetics, Part C (Applications and Reviews). 2009; 39(6):597-610.

[37] Singh S, Bandyopadhyay MN. Dissolved gas analysis technique for incipient fault diagnosis in power transformers: a bibliographic survey. IEEE Electrical Insulation Magazine. 2010; 26(6):41-6.

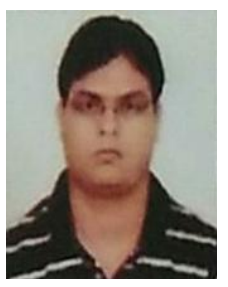

Anurag Tamrakar had completed his BE from Takshila Institute of Engineering \& Technology, Jabalpur, MP in 2009 in the Department of Electrical and Electronics. $\mathrm{He}$ completed his M.Tech in the Department of Electrical and Electronics from Gyan Ganga College of Technology, Jabalpur, MP. Currently he is pursuing PhD in the department of Electrical and Electronics from Swami Vivekanand University, Sagar, MP. His research areas are Fault Diagnosis and Energy Systems.

Email: tamrakaranurag18@gmail.com 